\title{
Workshop Media Pembelajaran Berbasis Teknologi Informasi Dalam Menghadapi Revolusi Industri 4.0
}

\author{
T Heru Nurgiansah \\ Fakultas Keguruan dan Ilmu Pendidikan \\ Universitas PGRI Yogyakarta \\ email: nurgiansah@upy.ac.id
}

\begin{abstract}
The Industrial Revolution 4.0 era required the use of internet media in various areas of life including the field of education. The purpose of this devotional activity is to equip educators and prospective educators to be able to create technology-based learning media such as the use of Power Point media to make learning activities more interesting. The methods of devotion used are lectures, two-way discussions, and direct practice for participants of activities. The results of this activity managed to make participants able to use information technology-based learning media that will be a provision in future teaching activities.
\end{abstract}

Keywords: Learning Media, Information Technology, Industrial Revolution 4.0

\begin{abstract}
Abstrak
Era Revolusi Industri 4.0 mengharuskan penggunaan media internet dalam berbagai bidang kehidupan termasuk bidang pendidikan. Tujuan kegiatan pengabdian ini adalah untuk membekali para pendidik maupun calon pendidik agar mampu membuat media pembelajaran berbasis teknologi seperti penggunaan media Power Point agar kegiatan pembelajaran lebih menarik. Metode pengabdian yang digunakan adalah ceramah, diskusi dua arah, dan praktek langsung bagi peserta kegiatan. Hasil kegiatan ini berhasil membuat peserta mampu untuk menggunakan media pembelajaran berbasis teknologi informasi yang akan menjadi bekal dalam kegiatan mengajar kedepan.
\end{abstract}

Kata Kunci: Media Pembelajaran, Teknologi Informasi, Revolusi Industri 4.0

\section{PENDAHULUAN}

Inovasi media pembelajaran merupakan salah satu hal yang perlu dikembangkan dalam pembelajaran dalam setiap jenjang pendidikan, baik itu pendidikan dasar, menengah, sampai dengan perguruan tinggi. Arah penggunaan media tidak lagi berbasis manual atau tradisional seperti penggunaan media karton, kartu, dan plastik. Namun saat ini penggunaan media pembelajaran telah mencapai perkembangan pada revolusi industri 4.0 atau bisa dikatakan lebih modern. Pembelajaran tidak lagi didominasi oleh guru sebagai teacher centered, namun memerlukan peranan siswa yang lebih aktif dalam wujud student center learning atau pembelajaran yang berpusat kepada siswa. Selain itu, di era Revolusi Industri 4.0 sekarang ini dunia pendidikan mendorong agar kurikulum pendidikan sesuai dengan dinamika digital, internet of think, Artificial intelligence, bioteknologi, serta perkembangan pesat lainnya [1].

Era revolusi industri 4.0 lebih menekankan pada penggunaan akses internet sebagai pengejawantahan implementasi perkembangan teknologi. Guru dituntut untuk dapat menggunakan teknologi baik dalam menyampaikan materi ataupun dalam mencari materi pelajaran [2]. Penggunaan media 
pembelajaran dapat mempermudah guru dalam melaksanakan pembelajaran dan memudahkan peserta didik dalam proses belajar [3]. Kemudahan dalam kegiatan belajar mengajar akan memberikan kenyamanan bagi guru maupun peserta didik dalam kegiatan belajar di kelas.

Media pembelajaran yang baik akan membantu guru dalam menyelenggarakan proses pembelajaran yang baik pula, demikian juga sebaliknya jika media pembelajarannya terkesan asal-asalan maka proses pembelajaran pun akan berlangsung alakadarnya [4]. Media pembelajaran yang baik dan valid, dapat mencapai tujuan pembelajaran [5].

Dampak nyata pada pembelajaran terimbas pada sistem pembelajaran yang lebih mengedepankan penggunaan teknologi daring dalam pembelajaran. Pembelajaran siswa dapat dilakukan secara non tatap muka, dimanapun, dan kapanpan dapat terpantau. Peserta didik juga dapat melakukan tugas, bahkan dapat berinteraksi langsung dengan pendidik melalui teleconverence, maupun chatting dalam pembimbingan.

Pada era revolusi industri 4.0 penggunaan pembelajaran daring maksimal dilaksanakan 80 persen dari proses pembelajaran. Penggunaan daring dapat dilakukan dengan memberikan bahan-bahan pembelajaran di internet, evaluasi online, penggunaan media pembelajaran interaktif maupun sistem penilaian online. Pembuatan media pembelajaran yang membantu peserta didik untuk memahami pembelajaran dengan menggunakan Teknologi Informasi, merupakan kebutuhan yang mendesak untuk dipelajari. Media pembelajaran merupakan salah satu komponen penting pembelajaran [6]. Selain itu, peran guru dalam menciptakan pembelajaran yang efektif, efisien dan interaktif mutlak diperlukan [7].
Kelemahan saat ini, belum adanya pelatihan yang memadai untuk meningkatkan paradigma pendidik untuk lebih menguasai media pembelajaran berbasis daring. Pelatihan dengan mengedepankan kontekstualitas media pembelajaran yang dikuasai oleh pendidik dalam menciptakan pembelajaran berbasis Teknologi Informasi merupakan hal yang tidak dapat ditunta-tunda lagi.

\section{METODE PENGABDIAN}

Metode yang digunakan dalam pengabdian ini adalah ceramah berpariasi yang disertai tanya jawab bersama peserta kegiatan. Selain itu, kegiatan ini disertai praktek secara langsung oleh peserta kegiatan. Lokasi pelatihan dilaksanakan di Gedung Multimedia Unit 1 Universitas PGRI Yogyakarta J1. PGRI I Sonosewu No. 117 Daerah Istimewa Yogyakarta kode pos 55182.

Dengan dilakukannya praktik langsung pembuatan media pembelajaran berbasis teknologi informasi, diharapkan peserta kegiatan bisa membuatnya dan digunakan dalam kegiatan belajar mengajar.

Sasaran kegiatan workshop media pembelajaran berbasis teknologi informasi menghadapi revolusi industri ini adalah pendidik serta calon pendidik. Hal ini dimaksudkan agar menjadi bekal pengalaman yang berharga dalam memanfaatkan teknologi sehingga pembelajaran nantinya tidak lagi menjenuhkan. Jadwal kegiatan in idapat dilihat pada tabel 1 berikut :

Tabel 1 Jadwal Kegiatan

\begin{tabular}{|c|c|}
\hline Waktu & Acara \\
\hline \multicolumn{2}{|c|}{ Hari Pertama } \\
\hline $07.30-08.00$ WIB & Registrasi \\
\hline $08.00-09.00 \mathrm{WIB}$ & Pembukaan \\
\hline 09:00 - 11.30 WIB & $\begin{array}{c}\text { Materi I } \\
\text { "Perubahan } \\
\text { Paradigma } \\
\text { Pembelajaran }\end{array}$ \\
\hline
\end{tabular}




\begin{tabular}{|c|c|}
\hline \hline & $\begin{array}{c}\text { berbasis Revolusi } \\
\text { Industri 4.0" }\end{array}$ \\
\hline \multicolumn{2}{|c|}{ Hari Kedua } \\
\hline $08.00-11.30$ WIB & $\begin{array}{c}\text { Materi II } \\
\text { "Pembuatan } \\
\text { Media } \\
\text { Pembelajaran } \\
\text { Berbasis Teknologi } \\
\text { Informasi" }\end{array}$ \\
\hline \multicolumn{2}{|c|}{ Hari Ketiga } \\
\hline $08.00-11.30$ WIB & $\begin{array}{c}\text { Praktek Pembuatan } \\
\text { Media berbasis } \\
\text { Teknologi } \\
\text { Informasi }\end{array}$ \\
\hline $13.00-15.30$ WIB & $\begin{array}{c}\text { Pengumpulan } \\
\text { Media }\end{array}$ \\
\hline 15.30 - Selesai & Penutup \\
\hline
\end{tabular}

Kegiatan ini Diikuti oleh 46 peserta dari berbagai latar belakang profesi, seperti guru, mahasiswa, dan dosen.

\section{HASIL DAN PEMBAHASAN}

Pelaksanaan pengabdian ini dilakukan selama tiga hari penuh dengan membagi kegiatan menjadi tiga sesi. Sesi pertama di hari pertama kegiatan berupa pemaparan materi mengenai "Perubahan Paradigma Pembelajaran berbasis Revolusi Industri 4.0" selama 150 menit atau 2 jam 30 menit. Dilanjutkan dengan sesi kedua pada hari kedua dengan penyampaian materi tentang "Pembuatan Media Pembelajaran Berbasis Teknologi Informasi" selama 210 menit atau 3 jam 30 menit. Dan sesi ketiga di hari ketiga adalah praktek langsung pembuatan media pembelajaran berbasis teknologi informasi yang dalam hal ini berupa pemanfaatan microsoft power point yang dilaksanakan seharian penuh agar peserta mempunyai keleluasaan dalam membuat media pembelajarnnya.

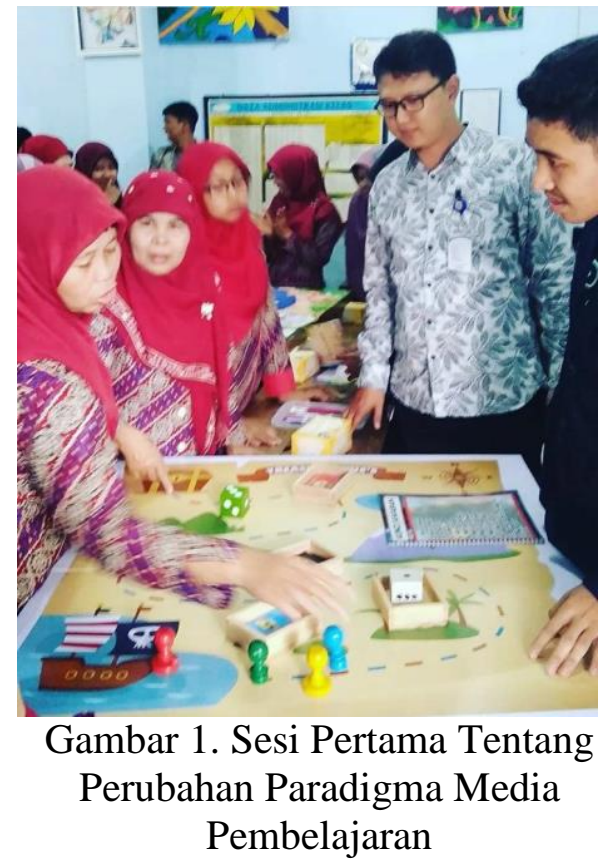

Tujuan dari pelaksanaan pengabdian ini, diantaranya untuk meningkatkan kemampuan pendidik untuk membuat media pembelajaran berbasis teknologi informasi. Kemudian memberi gambaran secara umum tentang pergeseran paradigma pembelajaran ke era revolusi industri 4.0. dan untuk mengembangkan kualitas pembelajaran dengan menyesuaikan diri dengan perkembangan jaman, kurikulum, dan arah pendidikan saat ini yang berbasis daring.

Pada kegiatan ini, para peserta tampak antusias dalam mengikuti tahap demi tahap kegiatan yang dilakukan. Untuk menghilangkan rasa jenuh, sesekali peserta diberikan game sebagai refleksi dan meningkatkan semangat.

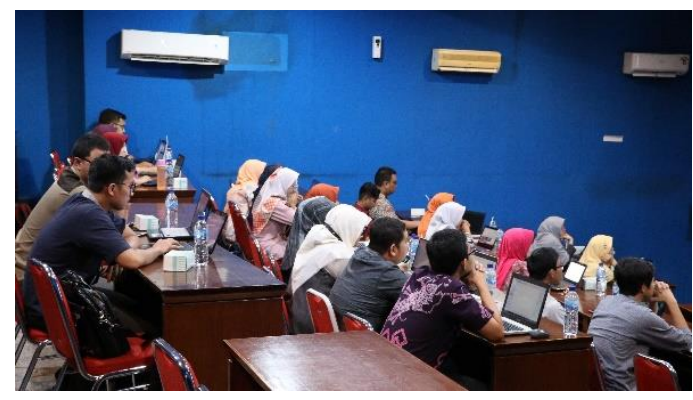


Gambar 2. Praktik Langsung Pembuatan Media Pembelajaran Berbasis Teknologi Informasi

\section{SIMPULAN}

Setelah mengikuti kegiatan pengabdian ini, para peserta berhasil dan mampu membuat media pembelajaran berbasis teknologi informasi. Kegiatankegiatan semacam ini perlu mendapat perhatian lebih karena memberikan manfaat yang signifikan terutama bagi kemajuan dunia pendidikan. Kegiatan pengabdian masyarakat pun menjadi salah satu dari Tridharma Perguruan Tinggi yang wajib dilaksanakan oleh dosen.

\section{UCAPAN TERIMAKASIH}

Penulis mengucapkan terima kasih kepada Lembaga Penelitian dan Pengabdian pada Masyarakat Universitas PGRI Yogyakarta dan Fakultas Keguruan dan Ilmu Pendidikan khususnya Program Studi Pendidikan Pancasila dan Kewarganegaraan atas dukungan morilnya sehingga pengabdian ini bisa terlaksana dengan baik. Terima kasih juga kepada peserta pengabdian baik guru, mahasiswa, maupun profesi lainnya yang tidak bisa penulis sebutkan satu persatu.

\section{DAFTAR PUSTAKA}

[1] T. H. Nurgiansah, "Pemutakhiran Kurikulum Pendidikan Kewarganegaraan di Era Revolusi Industri 4.0," Pros. Semin. Kewarganegaraan Univ. Negeri Medan, vol. 1, no. 1, pp. 95-102, 2019.

[2] E. Surachman, "Workshop Pemanfaatan Media Pembelajaran Sebagai Upaya Peningkatkan Efektifitas Pembelajaran Serta Profesionalitas Pendidik Di Smp Negeri 194 Jakarta," J. Sarwahita, vol. 13, no. 2, pp. 111-119, 2016, doi: 10.21009/sarwahita.132.06.

[3] N. Rani, Tundjung, and Y. B. Prasetya, "Workshop Media Pembelajaran Infografis Bagi Guru Mata Pelajaran Sebagai Media Pembelajaran Alternatif Di Madrasah Aliyah Tansyitul Muta'allimiin," J. Pengabdi. Masy., vol. 5, no. 2, pp. 60-66, 2015.

[4] I. Vita, "Pelatihan Pengembangan Media Pembelajaran Flash Guru SMA/SMK Muhammadiyah SeKabupaten Gunung Kidul," $J$. Pemberdaya., vol. 1, no. 2, pp. 427432, 2017.

[5] S. Fuada, "Pengujian Validitas Alat Peraga Pembangkit Sinyal (Oscillator) Untuk Pembelajaran Workshop Instrumentasi Industri," Pros. Semin. Nas. Pendidik., pp. 854-861, 2015.

[6] T. H. Nurgiansah and Y. Pringgowijoyo, "Pelatihan Penggunaan Model Pembelajaran Jurisprudensial Pada Guru Di KB TK Surya Marta Yogyakarta," KUAT Keuang. Umum dan Akunt. Ter. PKNSTAN, vol. 2, no. 1, 2020.

[7] R. M. Simanjorang and A. Sitohang, "PKM: Pelatihan Media Pembelajaran Berbasis TIK Menggunakan Aplikasi Open Source di SMA Prima Nusantara," TRIDARMA Pengabdi. Kpd. Masy. (PkM, vol. 2, no. 1, pp. 26-31, 2019, [Online]. Available: http://iocscience.org/ejournal/index .php/abdimas/article/view/537. 